\title{
Impact of Soiling Rate on Solar Photovoltaic Panel in Malaysia
}

\author{
Shaharin A. Sulaiman ${ }^{1 *}$, M. Rosman M. Razif ${ }^{1}$, Tan Dei $\operatorname{Han}^{1}$, Samson M. Atnaw ${ }^{2}, S$. \\ Norazilah A. Tamili ${ }^{3}$ \\ ${ }^{1}$ Department of Mechanical Engineering, Universiti Teknologi PETRONAS, 32610 Seri Iskandar, \\ Perak, Malaysia \\ ${ }^{2}$ Addis Ababa Science and Technology University, College of Electrical and Mechanical Engineering \\ ${ }^{3}$ Centre for Automotive Research \& Electric Mobility (CAREM), Research and Innovation, Universiti \\ Teknologi PETRONAS, 32610 Seri Iskandar,Perak.
}

\begin{abstract}
There are some weaknesses of using solar PV system especially when there is issue of soiling on the surface of solar PV panel. The consequences for absence of this such study can cause unanticipated cost in the operation of solar PV panel. The objective of this project is to study the trend of soiling rate over different time period and its effect on the performance of solar PV panel in Malaysia and to develop a simple prediction model for cleaning interval of solar PV system in Malaysia. The study was conducted on real-time basis on a building's roof. Measurements of solar irradiance, voltage, current and the mass of dust collected were performed from both clean and dirty panels. It was discovered that the Monthly Test was significant with $4.53 \%$ of performance drop. Further analysis was conducted by running prediction model for cleaning interval. Intersection of graph plotting and fixed cleaning cost gives answer of cleaning interval that can be performed. It can be concluded that for every two and half month is the recommended time interval to perform regular cleaning to maximise electrical power generation by solar PV system in Malaysia.
\end{abstract}

\section{Introduction}

The prices of non-renewable energy fluctuate making it sometimes less affordable to used. Therefore, there should be an alternative of energy usage. The alternative is by using renewable energy. One form of the renewable energy system that has huge potential to become alternative of electrical generation is solar photovoltaic system (PV). In Malaysia, solar PV system has huge potential to become main source for electric power generation since it receives high sun irradiation throughout the day. In addition, there are positive supports and efforts from the government side too.

\footnotetext{
* Corresponding author: shaharin@utp.edu.my
} 
For example, the establishment of Feed-in Tariff (FiT) that allows the owners of solar PV panel to sell their clean energy to distribution licensee for a fixed number of years [1]. Another major reason degradation of solar PV panel system is due to soiling rate on the panels. Soiling is a term for environmental factor that caused the accumulation of particles on the surface of solar PV panel, which prevents the solar radiation to interact with the solar PV cells. In the present work, the trend of soiling rate over different time period and its effect on the performance of solar PV panel was studied. In this study, mono-crystalline photovoltaic solar panel was used. This type of solar panel was chosen since it has the highest efficiency compared to the other type of solar PV panels. Using other type of solar PV panel can influence the accuracy of the study since it not represents real situation in Malaysia. This is because monocrystalline solar PV panel is the type that been widely used in Malaysia. The outcome of this project would enable to develop a simple prediction model for cleaning interval of solar PV system in Malaysia.

\section{Methodology}

In the present study, important steps related to the objective of the study were taken. Important data such as solar irradiance, voltage, current and mass of dust were collected. The data then was used to analyse the performance drop of solar PV panel.

\subsection{Location of experiment}

The experiment location is located at the rooftop of Research and Development Building Universiti Teknologi PETRONAS in Perak, Malaysia. This building is a four-storey height with a green building index certification. At the rooftop of the building, there is open space area. This open space area is allocated for solar PV panels side installation that used for renewable energy research and electricity.

\subsection{Experiment setup}

Figure 1 shows block diagram arrangement of solar PV panels and dummy glass panels with their circuit to the data logger and PC while the actual equipment set-up for the experiment is shown in Figure 2. These figures represent how the experiments were running. Generally, a pair of solar PV panels and dummy glass panels was used.

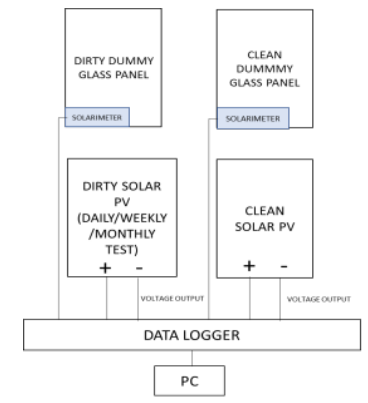

Fig. 1. Block diagram arrangement for dummy glass panels and solar PV panels

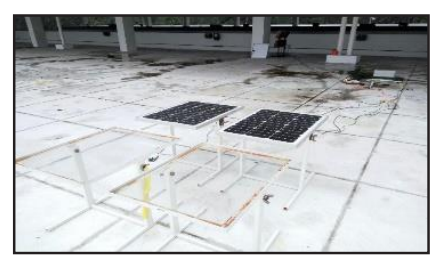

Fig. 2. Equipment set up.

Figure 3 shows the method on how the dust was being collected using the cloth. To obtain the mass of the dust, the mass of the cloth had been measured before wiped the surface of 
solar PV and after wiped the surface of solar PV. The difference in mass indicate the mass of the dust accumulate on the surface of solar PV.

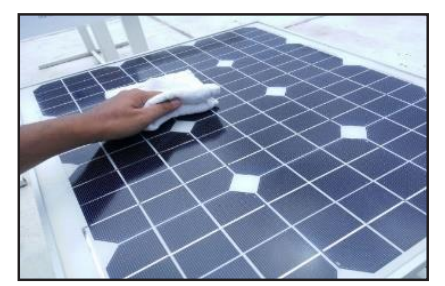

Fig. 3. Wiping surface of solar PV panel

\subsection{Experiment procedures}

In each experiment, the power output and solar irradiation from clean panels and dirty panels were measured simultaneously. The clean panels were used as a reference to determine performance drop of dirty panels. Four different tests were conducted which consist of daily, weekly, monthly and continuously monthly test. For each type of test, three-times data measurement have been taken. This was to ensure the consistency of result obtained. Table 1 shows the different between type of experiment conducted.

Table 1. Different experiment conducted on dirty panels to test measured periods for the dirty panels

\begin{tabular}{|c|c|c|c|c|}
\hline Test & Daily Test & Weekly Test & Monthly Test & $\begin{array}{c}\text { Continuous } \\
\text { Monthly Test }\end{array}$ \\
\hline $\begin{array}{l}\text { Days of dirty panels } \\
\text { been exposed to the } \\
\text { environment }\end{array}$ & 1 day & 7 days & 30 days & $\begin{array}{c}\text { Stating from day } 1 \\
\text { until end of experiment }\end{array}$ \\
\hline
\end{tabular}

\subsection{Experiment data testing}

Meanwhile, to achieve the second objective of the project, the following experimental procedure was performed. The data of performance drop from Continuous Monthly Test was converted into losses in RM.

\section{Results and discussions}

In this section, result and discussion is presented to study the soiling rate of solar PV panel in Malaysia. There were three type of test which were daily test, weekly test and monthly test. It was observed that the weather was good since there was no rain. All type of tests started from 10:00 until 17:00. Figure 4 and Figure 5 shows the trend of solar irradiance and variation of power generation with time for the monthly test

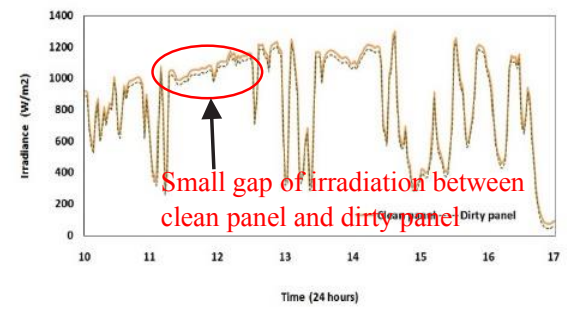

Fig. 4. Result of solar irradiance on monthly test

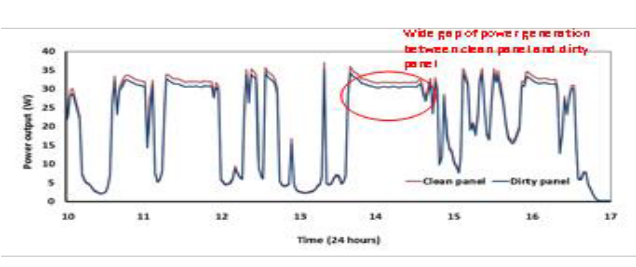

Fig. 5. Result of power output on monthly test 


\subsection{Daily test, weekly test and monthly test}

Figure 6 shows the relationship between the performance drop and mass of dust accumulated for daily test. For the overall figure, the trend can be observed when the mass of dust accumulated is increased, the performance drop also increased. the highest mass of dust collected is 0.015 gram that resulted the highest performance drop which is $0.59 \%$ for the daily test. Figure 7 shows the relationship between the performance drop and mass of dust accumulated. The trend that can observed from the figure is, when the mass of dust accumulated on solar PV increased, the performance drop is also increased. The highest mass of dust recorded for weekly test is $0.03 \mathrm{~g}$ with the highest performance drop which is $2.45 \%$. Figure 8 shows the relationship between the performance drop and mass of dust accumulated. For the overall figure, the trend can be observed when the mass of dust accumulated decreased, the performance drop also decreased. The highest mass of dust collected is 0.04 gram that resulted the highest performance drop which is $5.92 \%$ for the monthly test.

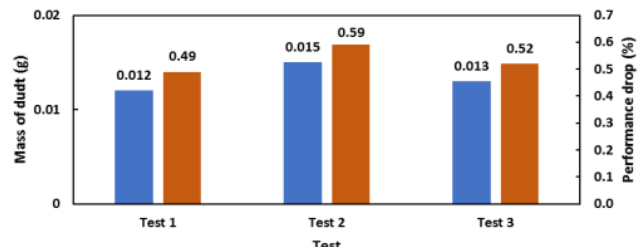

Fig. 6. Relationship between mass of dust and performance drop for daily test

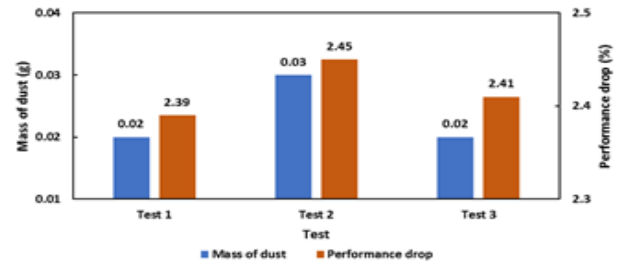

Fig. 7. Relationship between mass of dust and performance drop for weekly test

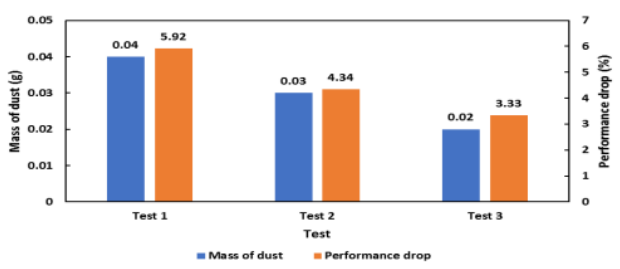

Fig. 8. Relationship between mass of dust and performance drop for monthly test

\subsection{Summary for All Test}

Comparison study and analysis has been conducted between the three types of test. The average mass of dust accumulated and average of performance drop from each type of test is being presented in Figure 9. In he left vertical axis represents the measurement of dust in gram while the right vertical axis represents the performance drop measurement of dirty solar PV panel. The blue bar charts are the average mass of dust for each type of test while the purple bar charts are the average performance drop for every type of test. From the figure, it can be concluded that the soiling rate and mass increase when the time taken for solar PV panel being exposed to the environment is longer. It can be concluded that the performance drop of Daily and Weekly Test was not significant but the monthly test was significant with $4.53 \%$ of performance drop. 


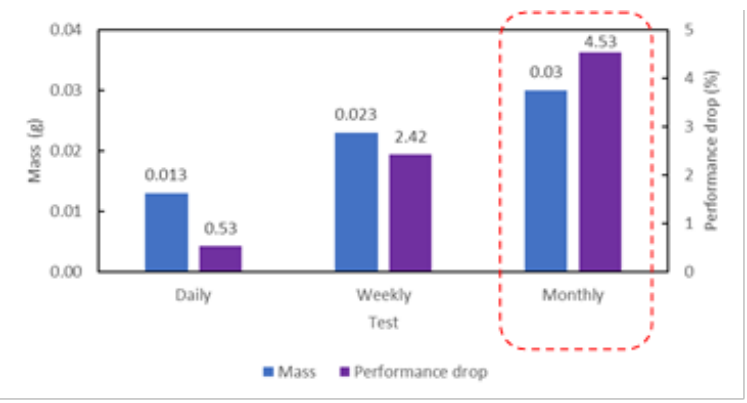

Fig. 9. Summary reading of all tests

\subsection{Prediction model for cleaning interval}

For industrial sector, solar power plant with capacity of $1000 \mathrm{~kW}$ is chosen as model plant. The losses calculation was constructed based on FiT tariff. In this calculation, industrial sector of solar power plant obtains FiT rates under RM 0.8819 per $\mathrm{kWh}$. From the industrial visit to Maju Perak solar power plant in Gopeng, Perak, the data obtained shows that cleaning cost for the plant capacity of $1000 \mathrm{~kW}$ is RM 6000 [15]. Therefore, it can be calculated that the cleaning cost for every $1 \mathrm{~kW}$ capacity is RM 6.00. Table 2 shows the cost of cleaning for respective of solar power plant capacity.

Table 2. Cleaning cost for respective solar power plant capacity

\begin{tabular}{|c|c|c|c|c|c|}
\hline $\begin{array}{c}\text { Time } \\
\text { (month) }\end{array}$ & $\begin{array}{c}\text { Performance } \\
\text { drop (\%) }\end{array}$ & $\begin{array}{c}\text { Energy } \\
\text { losses } \\
\mathbf{( k W )}\end{array}$ & $\begin{array}{c}\text { Estimated } \\
\text { irradiation } \\
\text { per day } \\
\text { (h) }\end{array}$ & $\begin{array}{c}\text { Losses } \\
\text { per } \\
\text { day } \\
\text { (RM) }\end{array}$ & $\begin{array}{c}\text { Monthly } \\
\text { losses } \\
\text { (RM) }\end{array}$ \\
\hline 1st & 5.85 & 58.5 & 2 & 103.18 & 3095.47 \\
\hline 2nd & 10.26 & 102.6 & 2 & 180.97 & 5428.98 \\
\hline 3rd & 13.59 & 135.9 & 2 & 239.70 & 7191.01 \\
\hline 4th & 17.59 & 175.9 & 2 & 310.25 & 9307.57 \\
\hline
\end{tabular}

Figure 10 shows the performance drop for Continuous Monthly Test. The vertical axis represents the performance drop and horizontal axis represents the monthly test basis. In the first month which was on August 2017, the performance drop of solar PV panel that recorded was $5.85 \%$, followed by the second month (September 2017) which was $10.26 \%$, third month (October 2017) which was $13.59 \%$ and fourth month (November 2017) was 17.59\%. Table 3 shows the amount of loses per month for $1000 \mathrm{~kW}$ model plant. The data of performance drop used in the table was from Continuous Monthly Test. Figure 11 shows the graph of Monthly Losses (RM) against Time (month) for 1000kW model plant.

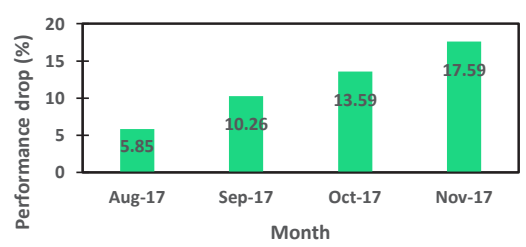

Fig. 10. Summary reading of all test

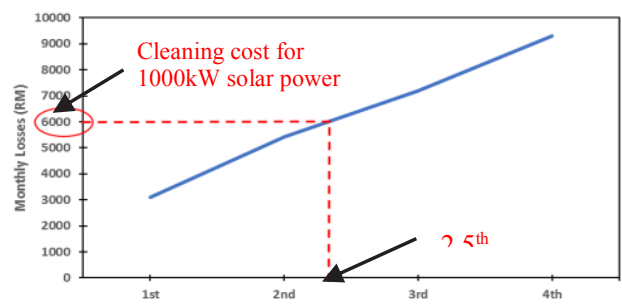

Fig. 11. Graph of Monthly Losses (RM) against Time (month) for $1000 \mathrm{~kW}$ model plant 
Table 3. Amount of losses for $1000 \mathrm{~kW}$ model plant

\begin{tabular}{|c|c|}
\hline Solar power plant capacity (kW) & Cleaning cost (RM) \\
\hline 1 & 6 \\
\hline 12 & 72 \\
\hline 1000 & 6000 \\
\hline
\end{tabular}

\section{Conclusions}

The present study has successfully shows the trend of soiling rate over different time period and its effect on the performance of solar PV panel. This would enable regular scheduling of cleaning of solar PV panels by the operators of the systems. As the time for solar panel being exposed to the environment is longer, the performance drop of solar PV panel is higher. The performance drops of daily and weekly test was not significant but the monthly test was significant with $4.53 \%$ of performance drop. It is recommended to perform regular cleaning on every two and half month after first cleaning in order to maximise electrical power generation and the profit gain by solar PV panel in Malaysia.

The authors would like to give a million thanks to Mechanical Engineering Department, Universiti Teknologi PETRONAS for their support and providing tuition fees for this conference. And also a great thanks to committee members of UTP-UMP-VIT Symposium on Energy Systems (SES) 2018.

\section{References}

1. Ahmad, S., Tahar, R. M., Muhammad-Sukki, F., Munir, A. B. \& Rahim, R. A. Energy, 84, 808-815 (2015)

2. Green, P. IEEE 34th International, IEEE, 1-9 (2012)

3. Maghami, M. R., Hizam, H., Gomes, C., Radzi, M. A., Rezadad, M. I. \& Hajighorbani, S. Renewable and Sustainable Energy Reviews, 59, 1307-1316 (2016)

4. Asl-Soleimani, E., Farhangi, S. \& Zabihi, M. S., Renewable Energy, 24, 459-468 (2001)

5. Maghami, M., Hizam, H., Gomes, C., Hajighorbani, S. \& Rezaei, N. PLOS ONE, 10, (2015)

6. Darwish, Z. A., Kazem, H. A., Sopian, K., Al-Goul, M. A. \& Alawadhi, H. Renewable and Sustainable Energy Reviews, 41, 735-744 (2015) 